\title{
Acessibilidade de cadeirantes em clínicas de fisioterapia do Plano Piloto de Brasília - DF
}

\author{
Larissa Sales Brito* \\ Márcia Corrêa Matos* \\ Marinha Tereza Alves Nascimento** \\ Denise Ribeiro Rabelo da Silva ${ }^{* * *}$
}

RESUMO - Este estudo visa avaliar as condições de acesso e utilização de clínicas de fisioterapia do Plano Piloto de Brasília, por pessoas que fazem uso de cadeira de rodas para locomoção. Foram visitadas quarenta clínicas particulares de fisioterapia durante os meses de setembro e outubro de 2006, a fim de avaliar condições e medidas de vagas para veículos, rampas, elevadores sociais, portas de acesso principal, áreas de circulação interna e sanitários, confrontando-as com a norma NBR 9050:2004 da ABNT. Nenhuma clínica apresentou completa condição de acesso em todos os itens; no sanitário, as características estavam menos adequadas. Apesar da existência da legislação e das normas em vigor, há barreiras arquitetônicas que impedem os portadores de deficiência física de exercer a plena cidadania. É necessária maior conscientização da sociedade e fiscalização efetiva para garantir a inclusão social.

Palavras-chave: Acessibilidade. Barreiras arquitetônicas. Deficiência.

\section{Accessibility of users of wheel chair in clinics of physiotherapy in the center of Brasília - DF}

\begin{abstract}
This study aims to evaluate the access conditions and use of physiotherapy clinics in the center of Brasília - DF for people that use wheel chair for locomotion. Forty private physiotherapy clinics were visited between september and october of 2006 to evaluate the conditions and measurements of vacancy for vehicles, ramps, elevators, main access doors, internal circulation areas and public restrooms, in accordance with the NBR 9050:2004 norm of ABNT. No clinic presented a complete access condition for all of the items, and the restrooms were the most inadequate. Despite the current legislation and norms, there are still many architectural barriers which disturb people with disabilities from exerting their full citizenship. A wider awareness in the society and strong supervision by the authorities are necessary to guarantee their inclusion in the society.
\end{abstract}

Keywords: Accessibility. Architectural barriers. Physical deficiency.

\footnotetext{
Graduadas em Fisioterapia - UniCEUB - sales.larissa@gmail.com, mcorreamatos@ yahoo.com.br

** Professora do Curso de Fisioterapia - UniCEUB - tereza.marinha@uol.com.br

Especialista em Ortopedia e Traumatologia e Professora do Curso de Fisioterapia - UniCEUB deniserabelo@gmail.com
} 


\section{Introdução}

A Norma Brasileira de Acessibilidade a edificações, mobiliário, espaços e equipamentos urbanos (ABNT / NBR 9050:2004) define acessibilidade como "possibilidade e condição de alcance, percepção e entendimento para a utilização com segurança e autonomia de edificações, espaço, mobiliário, equipamento urbano e elementos". A acessibilidade está fundamentada no direito universal de que todos tenham condições de ir e vir livremente (LOPES FILHO, 2006.).

Promover a acessibilidade significa remover barreiras arquitetônicas, urbanísticas ou ambientais que impeçam a aproximação, a transferência ou a circulação (ABNT, 2004). Segundo Guimarães (2002), professor da Escola de Arquitetura da UFMG, as pessoas que não conseguem sobrepor-se aos problemas de mobilidade e de orientação espacial podem desenvolver baixa auto-estima, depressão, angústia e revolta.

O Desenho Universal visa à construção de espaços que garantam a universalização do acesso e que possam ser utilizados, de maneira independente e igual, por todos (NICHOLL; BOUERI FILHO, 2001). A melhoria das condições de acesso deve considerar a necessidade de pessoas excessivamente altas ou baixas, com mobilidade reduzida, como idosos, crianças, portadores de deficiência permanente ou temporária, cardiopatas, obesos, gestantes, que fazem uso de auxílio-locomoção, entre outros (OLIVEIRA, 2003). Essas pessoas são impedidas de exercer plenamente a cidadania, o direito de ir e vir e o acesso à educação, à saúde, ao lazer, ao emprego, pois as barreiras arquitetônicas dificultam a circulação em ambientes construídos (BITTENCOUT et al., 2004). Segundo Lopes Filho (2006, p. 1), arquiteto especialista em acessibilidade, "Prover o acesso para todos é ainda um grande desafio que enfrentamos, e este objetivo somente será atingido com a eliminação das barreiras arquitetônicas urbanísticas, da edificação, do transporte e da comunicação".

De acordo com o último censo demográfico da Fundação Instituto de Geografia e Estatística (IBGE, 2000), 14,5\% da população brasileira são portadores de, pelo menos, um tipo de deficiência mental, física, visual ou auditiva. Desse total, $0,16 \%$ encontra-se no Distrito Federal, o que significa o número de 275.580 portadores de deficiência. Segundo a Organização Mundial de Saúde (OMS), as principais causas da deficiência no Brasil são subnutrição, anomalias congênitas e perinatais, acidentes de 
trânsito e de trabalho, infecções e violência (MAUCH, 2004.). Outros fatores, como traumas e lesões, epidemias, falta de saneamento básico, programas inadequados de assistência social, saúde e educação, contaminação no meio ambiente, uso imprudente de drogas, doenças transmissíveis e patologias crônicas degenerativas também são potenciais causadores de deficiência (LASCIO et al., 2000). O termo pessoa portadora de deficiência é o que melhor define esse indivíduo, que é, acima de tudo, é um ser humano (COHEN, 1998).

A NBR 9050 da Associação Brasileira de Normas Técnicas (ABNT, 2004), tem como objetivo proporcionar à maioria das pessoas, de qualquer idade, estatura ou com limitação de mobilidade ou percepção, a utilização, de modo autônomo e seguro, do ambiente, das edificações, do mobiliário, dos equipamentos urbanos e dos elementos. Há a previsão de que espaços, edificações, mobiliário e equipamentos urbanos, posteriormente projetados, construídos, montados ou implantados, suas reformas e ampliações devem cumprir o contido nesta norma para serem considerados acessíveis.

Leis e decretos foram elaborados para garantir os direitos das pessoas portadoras de deficiência. Entre eles, a Lei No 7.853/89que define a Política Nacional de Integração da Pessoa Portadora de Deficiência em múltiplos aspectos (BRASIL, 1989), regulamentada pelo Decreto $N^{0} 3.298 / 99$ que estabelece o respeito, a inclusão social, a não-discriminação, o acesso, o ingresso e a permanência da pessoa portadora de deficiência em todos os serviços oferecidos à comunidade, entre outros princípios (BRASIL, 1999).

Em 2000, foi elaborada a lei $\mathrm{N}^{\circ} 10.048 / 00$, que dá prioridade de atendimento e outras providências às pessoas portadoras de deficiência física, idosos com idade igual ou superior a 65 anos, gestantes, lactantes e pessoas acompanhadas por criança de colo, trazendo importantes inovações no atendimento a esse grupo (BRASIL, 2000a). Também foi publicada a lei $\mathrm{N}^{\circ} 10.098 / 00$, que estabelece normas gerais, critérios básicos e dá outras providências para a promoção da acessibilidade de pessoas portadoras de deficiência ou com mobilidade reduzida, mediante a remoção de barreiras e obstáculos nas vias e nos espaços públicos, no mobiliário urbano, na construção e na reforma de edifícios e nos meios de transporte e comunicação (BRASIL, 2000b).

A Lei $n^{\circ}$. 2.105/98, regulamentada pelo Decreto $n^{\circ}$. 19.915/98 dispõe sobre o Código de Edificações do Distrito Federal (DISTRITO FEDERAL, 1998). A sessão IV, 
sobre acessibilidade, traz, no artigo 122, que, "em toda edificação de uso público e coletivo, serão garantidas condições de acesso físico, livre de barreiras arquitetônicas, inclusive a pessoas com dificuldade de locomoção". Todas as novas edificações são aprovadas e executadas se estiverem de acordo com os padrões de acessibilidade estabelecidos nesse código, recebendo, assim, o alvará de construção (MUNIZ, 2005). Após a conclusão da obra, é emitida a certidão do habite-se, um documento que atesta que o imóvel foi construído seguindo-se as exigências (legislação local) estabelecidas para a aprovação do projeto (PEZENTE, 2006).

Apesar da legislação e das normas existentes, as condições de acesso fornecidas pela sociedade são inadequadas. Falta obrigatoriedade e conexão entre as leis e os parâmetros antropométricos estabelecidos na NBR 9050 (ABNT, 2004). Questiona-se

que essas condições não se adaptam, em sua maioria, a necessidades, limitações e capacidades dos portadores de deficiência, submetidos, assim, ao processo de exclusão social pela falta de oportunidades de exercer a cidadania e garantir o direito de ir e vir livremente com autonomia e segurança. A inacessibilidade, a desigualdade e a discriminação não lhes possibilitam boa qualidade de vida. A inclusão social é garantida pela remoção de barreiras e pelo cuidado para que elas não venham a existir, atendendo às necessidades dos portadores de deficiência (OLIVEIRA, 2003).

Nesse contexto, observando as dificuldades dos portadores de deficiência em transpor as barreiras arquitetônicas existentes, o objetivo principal deste trabalho é avaliar a adequação de algumas clínicas particulares de Fisioterapia do Plano Piloto de Brasília segundo a NBR 9050 da ABNT.

\section{Metodologia}

Esse trabalho consiste em estudo transversal descritivo sobre as condições de acesso e utilização de algumas clínicas de Fisioterapia do Plano Piloto de Brasília por cadeirantes - pessoas que fazem uso de cadeira de rodas para locomoção. Foram visitadas quarenta clínicas particulares de Fisioterapia do Plano Piloto de Brasília, durante os meses de setembro e outubro de 2006. Para a escolha da amostra por conveniência, foi encaminhada uma carta ao Conselho Regional de Fisioterapia e Terapia Ocupacional, para solicitar uma lista com nome, endereço e telefone das 
clínicas registradas. Apesar de garantido o sigilo e a não-utilização dos dados das clínicas fora do ambiente técnico-científico, o Conselho não concedeu a listagem, alegando que as informações são confidenciais e que deve ser garantida a segurança dos fisioterapeutas. Por essa razão, foi realizada pesquisa nos nos catálogos Listel e Telelistas 2006/2007 e no sites das mesmas (www.listaonline.com.br e www.telelistas.com.br), para compor a amostra.

As clínicas de Fisioterapia foram escolhidas por tratar-se de estabelecimentos que atendem pessoas portadoras de deficiências físicas, incluindo cadeirantes, e que deveriam realizar adaptações para proporcionar condições seguras de acesso aos pacientes. As clínicas foram visitadas previamente para que os objetivos do estudo fossem esclarecidos. Naquelas em que o responsável não se encontrava, foi entregue uma carta que explicava os objetivos e solicitava a autorização para a realização do estudo.

Foram incluídos os estabelecimentos registrados como clínicas e que autorizaram a pesquisa, independente da área de atuação. Os centros de reabilitação assinaram um termo de aceite para o controle da pesquisa. A maioria considerou o tema interessante e foi receptiva durante a visita. Foram excluídos os locais registrados como consultório, clínicas não-localizadas pela ausência de dados atualizados e corretos nas listas consultadas e aqueles que não autorizaram a realização do estudo ou os que não deram qualquer resposta. Segundo a Resolução COFFITO - 37/84 (COFFITO, 1984) são consideradas clínicas, os estabelecimentos que possuem registro de pessoa jurídica como empresa (CNPJ) e em que estejam em atividade profissional fisioterapeutas, em número condizente com a quantidade de clientes e a natureza do atendimento.

As visitas foram realizadas em horários determinados pelas clínicas, preferencialmente nos intervalos de atendimento ou em períodos de baixo funcionamento. Durante a visita, foram avaliadas condições e medidas de vagas para veículos, rampas, elevadores sociais, portas de acesso principal, áreas de circulação interna e sanitários, confrontando-as com as normas da NBR 9050 da ABNT. O instrumento utilizado para coleta das medidas foi uma trena Starrett de cinco metros. As medidas e as observações foram registradas em tabelas e classificadas, posteriormente, quanto ao nível de adequação, em "atende", "não atende" e "não se aplica". 
O resultado estatístico foi realizado nos programas Microsoft Excel e Microsoft Office Access. As medidas que estavam de acordo com os parâmetros estabelecidos na NBR 9050 (ABNT, 2004), adequadas aos cadeirantes, foram classificadas como "atende". A norma permite tolerância dimensional de, aproximadamente, $10 \mathrm{~mm}$, exceto para sanitários, pois os valores identificados como máximos e mínimos devem ser considerados absolutos nesse item. As características com valores inadequados, ou seja, fora dessa tolerância dimensional, foram classificadas como "não atende", e, na ausência do item avaliado, a classificação, em todos os aspectos, foi "não se aplica".

Segundo a NBR 9050, as características dos itens citados devem ter as seguintes condições e medidas:

\section{Vagas para veículos:}

- Sinalização horizontal e vertical;

- Espaço adicional de, no mínimo, 1,20 m;

- Rebaixamento de guias;

- Localizadas próximas ao acesso principal;

- Pelo menos, uma vaga reservada em estacionamento com número total de vagas de onze a cem.

\section{Rampa:}

- Largura livre com o mínimo admissível de 1,20 m;

- Ressaltos laterais de paredes ou guias de balizamento com altura mínima de $0,05 \mathrm{~m}$;

- Patamares de dimensão longitudinal mínima admissível de 1,20 m no início e no término da rampa;

- Inclinação de até $12,5 \%$;

- Piso regular, firme, estável e antiderrapante.

\section{Elevador (deve atender ao disposto na ABNT NBR 13994, 2000):}

- Espelho interno;

- Altura dos botões de 1,35 m do centro do botão mais alto ao piso (tolerância de $25 \mathrm{~mm}$ );

- Largura da porta de, no mínimo, 0,80 m;

- Área de, no mínimo, 1,40 x 1,10 m.

\section{Porta de acesso principal:}

- Largura de, no mínimo, 0,80 m;

- Tipo de abertura com movimento único e maçaneta de alavanca;

- Altura da maçaneta: entre 0,90 e 1,10 m. 


\section{Circulação interna (corredores):}

- Largura de, no mínimo, 0,90 m;

- Piso regular, firme, estável e antiderrapante.

\section{Sanitário:}

- Localizado próximo à circulação principal, acessível;

- Área interna de, no mínimo, 1,50 x 1,70 m;

- Piso regular, firme, estável e antiderrapante.

\section{Barras de apoio:}

- Localização lateral e no fundo da bacia sanitária;

- Comprimento de, no mínimo, 0,80 m;

- Altura de 0,75 m do piso.

\section{Bacia sanitária:}

- Área de transferência para bacia sanitária de 1,20 x 0,80 m;

- Altura de 0,43 a 0,46 m do piso com o assento.

\section{Descarga:}

- Altura de $1 \mathrm{~m}$ do centro ao piso;

- Acionamento automático ou por alavanca.

\section{Papelaria:}

- Altura:

a) embutida: de 0,50 a $0,60 \mathrm{~m}$ do piso;

b) não-embutida: de 1,00 a 1,20 m;

- Distância:
a) embutida: máximo de $0,15 \mathrm{~m}$ da borda frontal;
b) não-embutida: alinhada à borda frontal.

\section{Lavatório:}

- Altura: de 0,78 a 0,80 m;

- Vão livre: mínimo de $0,73 \mathrm{~m}$;

- Cifão e tubulação: mínimo de 0,25 m da face externa frontal;

- Proteção de cifão;

- Acionamento da torneira: alavanca ou sensor eletrônico;

- Distância da torneira: máximo de $0,50 \mathrm{~m}$ da face externa frontal.

\section{Espelho vertical:}

- Altura:

a) Vertical: máximo de $0,90 \mathrm{~m}$ da borda inferior ao piso;

b) Inclinado: máximo de 1,10 m da borda inferior ao piso. 


\section{Resultados}

Das quarenta clínicas avaliadas, nenhuma apresenta completa condição de acesso em todos os itens, de acordo com a NBR 9050 da ABNT, para receber pessoas que fazem uso de cadeira de rodas para locomoção.

De acordo com a figura 1 , referente às vagas para veículos, apenas uma clínica $(2,5 \%)$ não possui estacionamento próprio, sendo por isso classificada como não se aplica. Nas demais, oito (20\%) possuem espaço adicional, 29 (72,5\%) possuem número adequado de vagas reservadas para portadores de deficiência física, 27 (67,5\%) estão próximas ao acesso principal, 28 (70\%) apresentam rebaixamento de guias, 22 (55\%) possuem a sinalização horizontal, e 21 (52,5\%), a sinalização vertical.

Figura 1 - Porcentual e número de clínicas que atenderam ou não às características necessárias para as vagas de veículos.

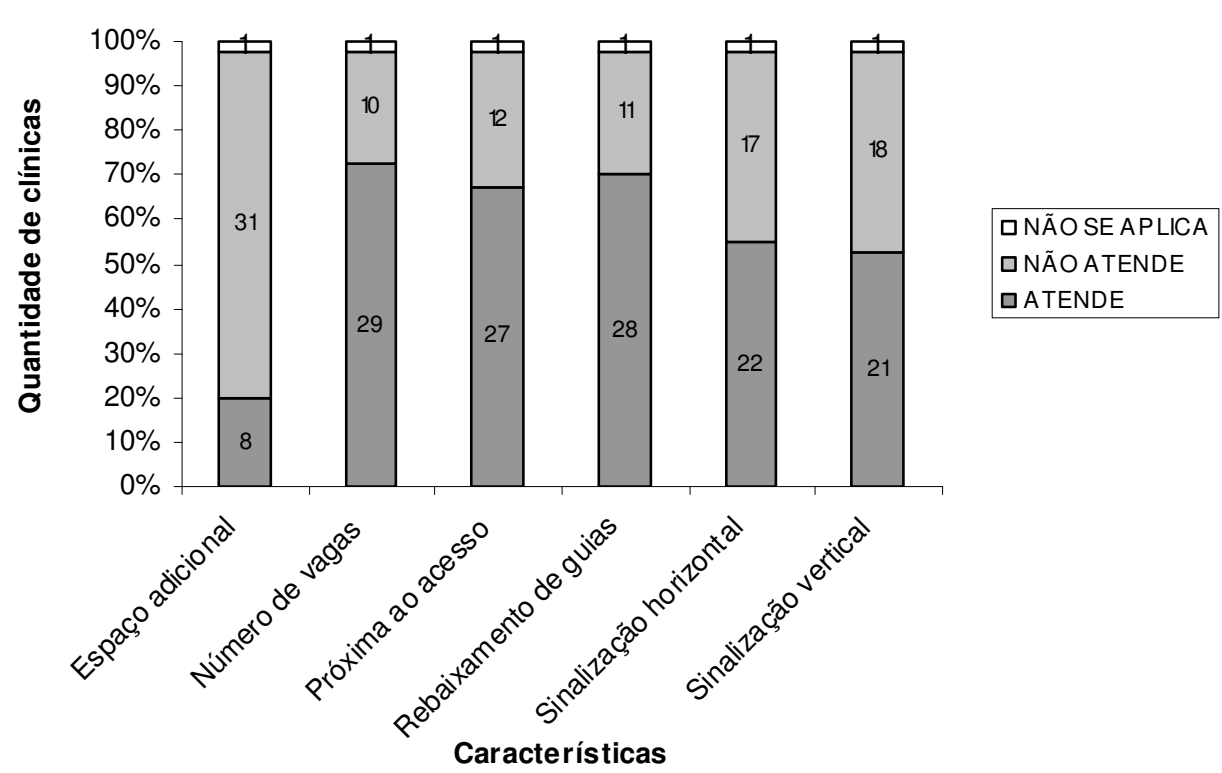

O item rampas, representado na figura 2, foi classificado como não se aplica em dezesseis (40\%) clínicas. Em sete casos (17,5\%), a inclinação é adequada, doze (30\%) apresentam a largura livre permitida, dezesseis $(40 \%)$ apresentam patamares, quatorze 
(35\%) apresentam o piso de acordo com as normas, e oito (20\%) possuem ressaltos laterais.

Figura 2 - Porcentual e número de clínicas que atenderam ou não as características necessárias para as rampas.

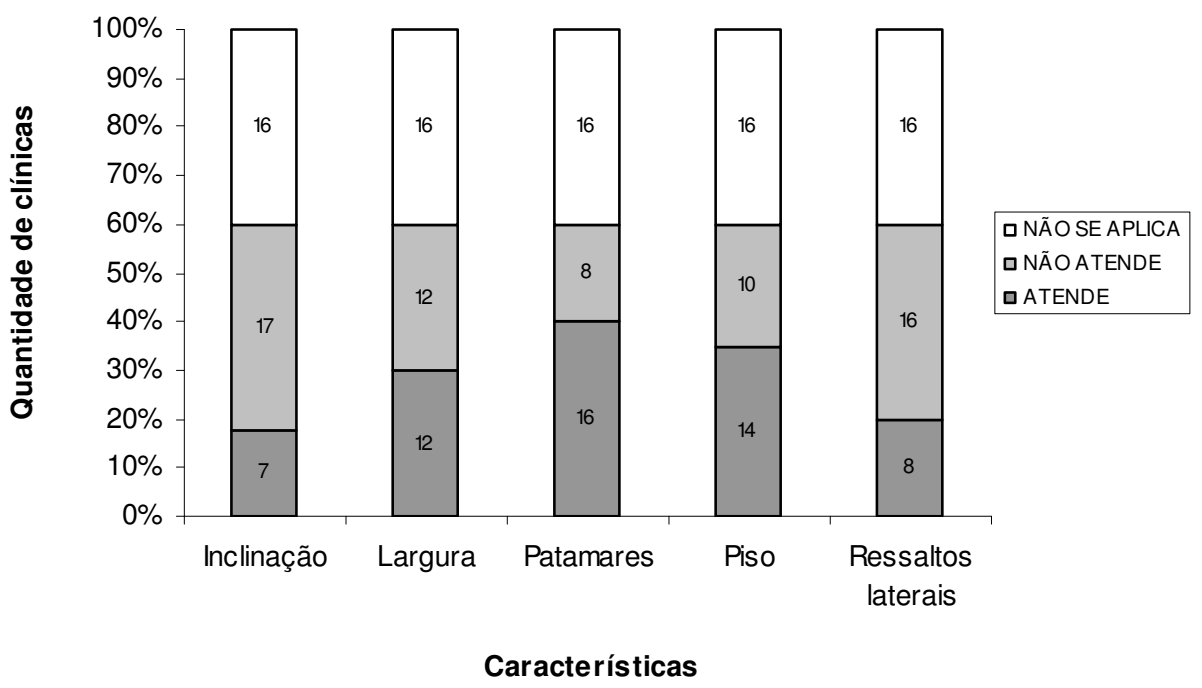

A figura 3 define as condições dos elevadores. Doze (30\%) clínicas encontramse no térreo, e, por essa razão, a avaliação nos elevadores não se aplica. Nas demais, treze $(32,5)$ possuem altura dos botões de acordo com a norma, dezesseis $(40 \%)$ apresentam área adequada, 21 (52,5\%) possuem espelho interno, e, em 26 (65\%), a largura da porta é apropriada.

Conforme pode ser observado na figura 4 , a porta de acesso principal possui altura da maçaneta adequada em 35 (87,5\%), a largura mínima, em 24 (60\%), e o tipo de abertura correto, em nove $(22,5 \%)$ das clínicas pesquisadas.

A figura 5, referente ao item área de circulação interna, mostra que treze $(32,5 \%)$ clínicas apresentavam os corredores com largura mínima correta, e 38 (95\%) possuem piso nas condições indicadas na norma. 
Figura 3 - Porcentual e número de clínicas que atenderam ou não as características necessárias para os elevadores.

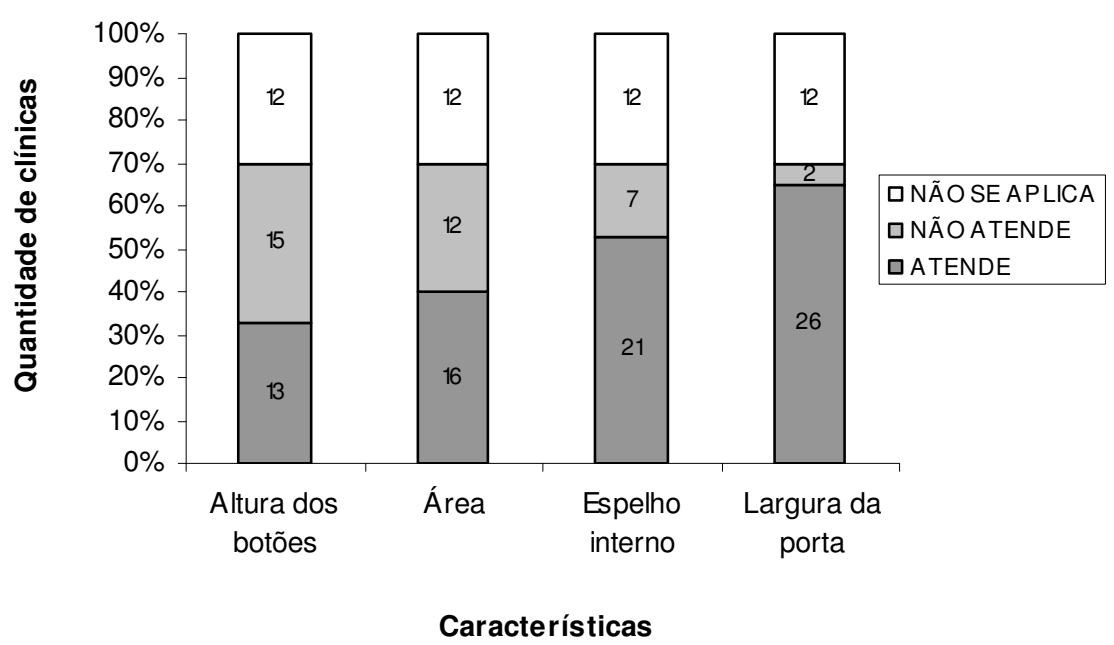

Figura 4 - Porcentual e número de clínicas que atenderam ou não as características necessárias para as portas de acesso.

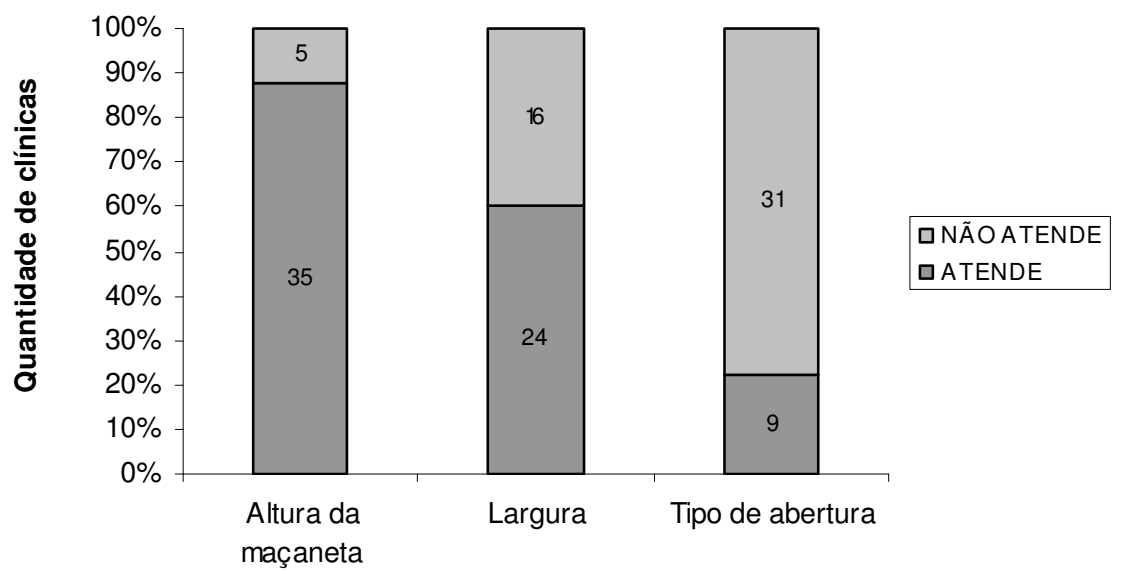

Características 
Figura 5 - Porcentual e número de clínicas que atenderam ou não as características necessárias para as portas de acesso.

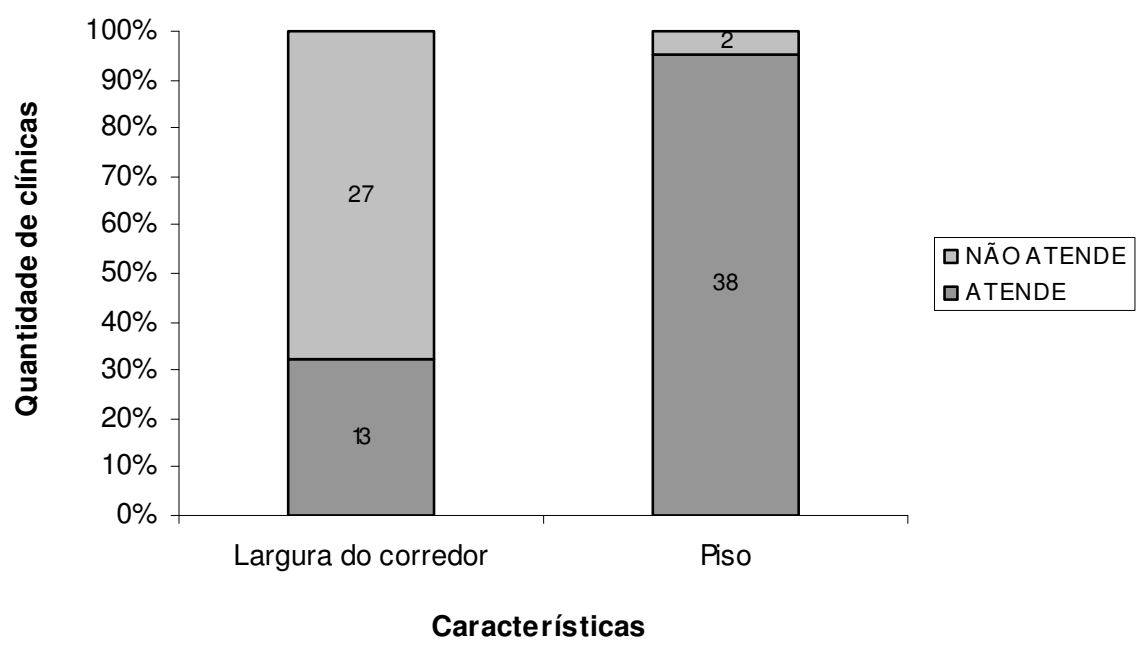

Os resultados da avaliação dos sanitários encontram-se nas figuras de 6 a 11 . Para os sanitários, 35 (87,5\%) localizam-se próximos à circulação principal e em rota acessível, doze (30\%) possuem a área adequada, e $36(90 \%)$, o piso de acordo com a norma. $\mathrm{Na}$ avaliação dos subitens de sanitários, observa-se que, em relação às barras de apoio, em uma (2,5\%) clínica, estão localizadas adequadamente, em duas (5\%), com comprimento ideal, e nenhuma, com altura adequada. A bacia sanitária possui a altura do assento de acordo com a norma e a área de transferência ideal em treze (32,5\%). O acionamento da descarga está apropriado em quinze (37,5\%), e sua altura em uma (2,5\%). Em relação à papelaria, onze (27,5\%) atendem quanto à altura, e quatro (10\%), quanto à distância. O lavatório possui altura acessível em nove (22,5\%), vão livre mínimo em 24 (60\%), cifão e tubulação com distância mínima da face externa frontal em quatro (10\%), cifão protegido em uma, acionamento da torneira adequado em doze (30\%) e distância da torneira indicada na norma em 38 (95\%). Em todas as clínicas que possuem espelho, este se apresenta na posição vertical, e quatro, estão na altura máxima permitida. 
Figura 6 - Porcentual e número de clínicas que atenderam ou não as características necessárias para os sanitários.

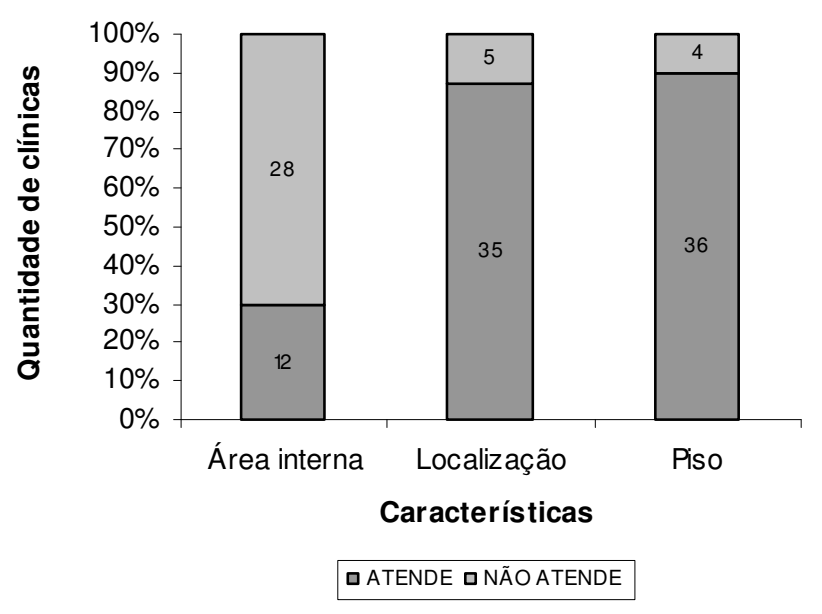

Figura 7 - Porcentual e número de clínicas que atenderam ou não as características relacionadas às barras de apoio nos sanitários.

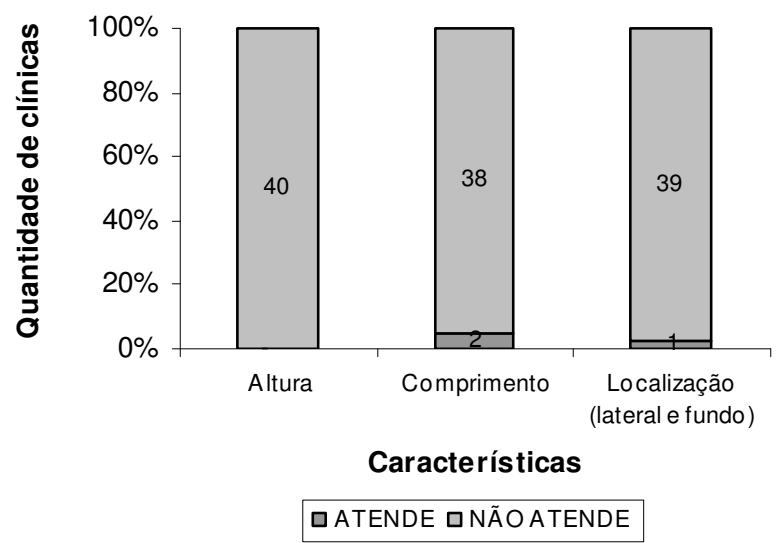

\section{Discussão}

A NBR 9050 (ABNT, 2004), estabelece critérios e parâmetros técnicos, visando proporcionar à maior quantidade possível de pessoas a utilização de maneira autônoma e segura do ambiente. Analisando os resultados, foi possível observar que todas as clínicas apresentavam algumas características inadequadas quando confrontadas com a norma, e nenhum item estava completamente correto. 
Figura 8 - Porcentual e número de clínicas que atenderam ou não as características relacionadas às bacias sanitárias.

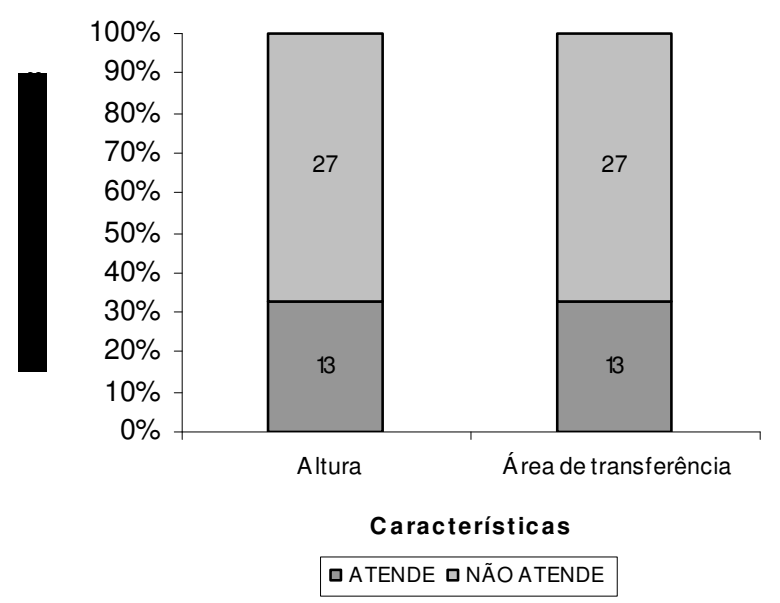

Figura 9 - Porcentual e número de clínicas que atenderam ou não as características relacionadas às descargas dos sanitários.

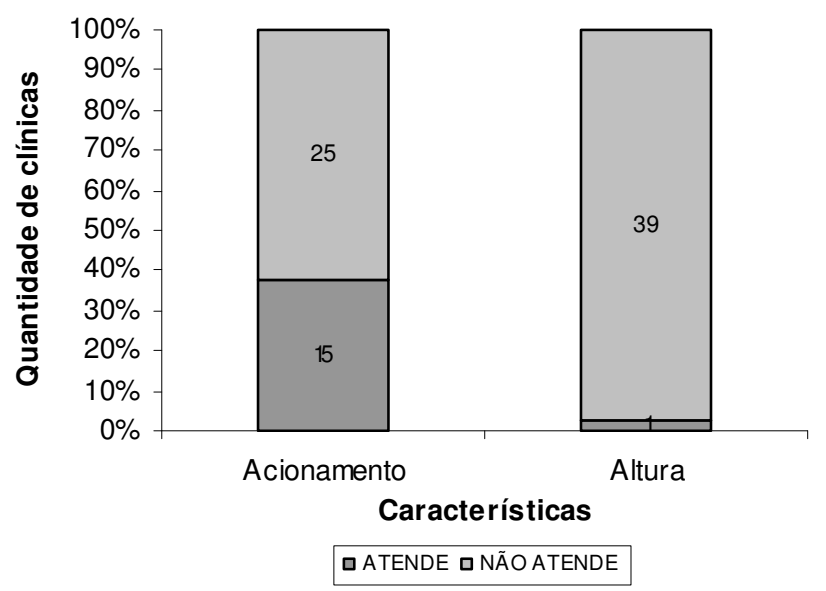

Figura 10 - Porcentual e número de clínicas que atenderam ou não as características relacionadas à papelaria disponível nos sanitários.

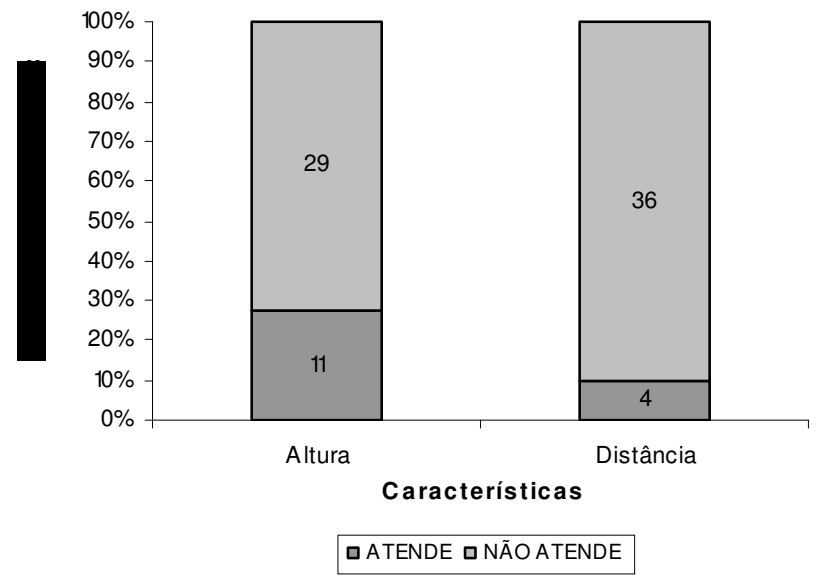


A maioria justificou que a falta de adequação dos ambientes ocorria pelo fato desses estabelecimentos não atenderem a pacientes neurológicos. Não consideraram que a utilização de cadeira de rodas também pode ser feita por idosos, portadores de deficiência temporária e com outras necessidades especiais.

Figura 11 - Porcentual e número de clínicas que atenderam ou não as características relacionadas aos espelhos e lavatórios disponíveis nos sanitários.

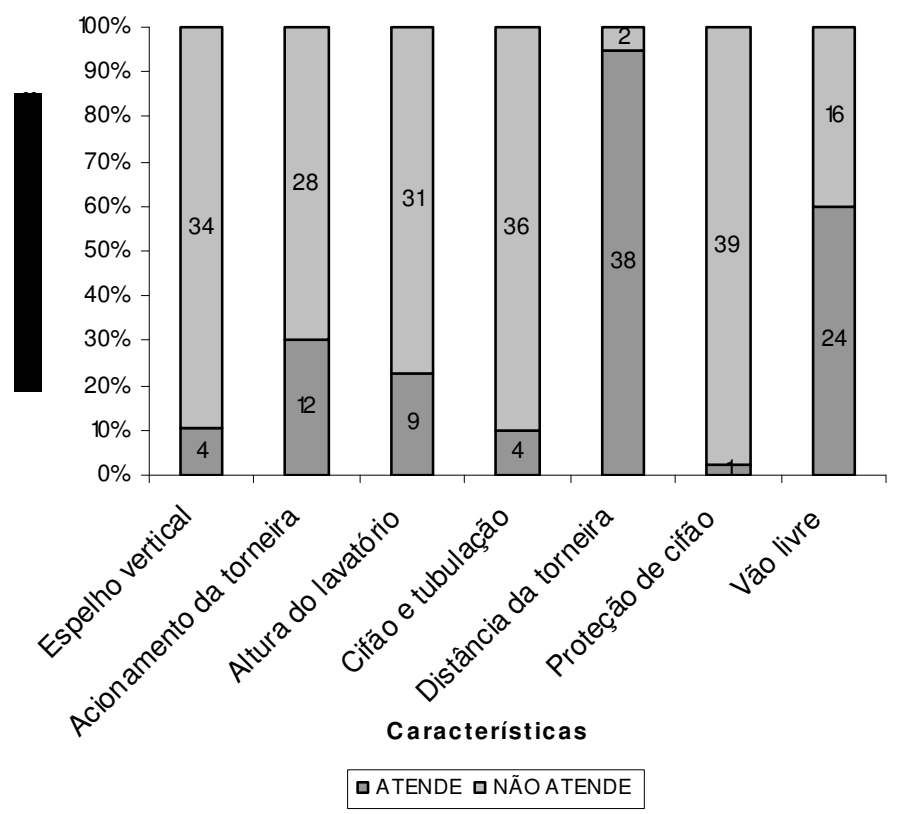

O ambiente avaliado que apresentou mais características inadequadas foi $\mathrm{o}$ sanitário, e, nele, apenas a localização, o piso e a distância da torneira do lavatório continham valores positivos. A maioria das clínicas não possuía banheiro exclusivo para portadores de deficiência física em suas dependências, adotando, dessa forma, medidas incompletas e ineficazes para adaptação. As clínicas alegam que os edifícios onde se encontram já possuem banheiros adaptados, exclusivos para portadores de deficiência física. Porém, os banheiros externos não foram visitados, pois o presente estudo apenas avaliou as dependências das clínicas.

$\mathrm{Na}$ maior parte dos edifícios, havia presença de vagas definidas para estacionamento de veículos que conduzam ou sejam conduzidos por pessoas portadoras de deficiência. Entretanto, o espaço adicional é a característica que menos se adapta às normas, não apresentando a dimensão necessária para a circulação de cadeira de rodas. 
Acredita-se que a norma não seja respeitada, para não diminuir o número total de vagas no estacionamento.

A maior parte das rampas avaliadas não oferecia segurança aos usuários de cadeira de rodas. A inclinação foi a característica que mais contribuiu para que isso ocorresse, pois as rampas são construídas sem o devido conhecimento da norma, apenas como medida paliativa e solução impensada. Entre as características avaliadas no item porta de acesso, o tipo de abertura estava inadequado na maioria das clínicas. Apesar disso, o acesso não é prejudicado, pois, em quase todas, a porta principal já se encontra aberta durante o período de funcionamento.

As clínicas que apresentaram, pelo menos, um corredor com largura mínima inadequada foram classificadas como "não atende". Os responsáveis e ou proprietários alegaram que, caso seja necessário atender cadeirantes, a mobília pode ser modificada ou pode-se fazer uso de outra porta, dispensando a circulação da cadeira de rodas pelos corredores da clínica. Muitos justificaram que as condições de acesso não são respeitadas, porque os pacientes que fazem uso de cadeira de rodas podem ser atendidos a domicílio. Entretanto, essa medida pode não ser a melhor para o paciente, já que um dos objetivos da reabilitação é o retorno à vida social.

Oliveira et al. (2005) avaliaram as condições de acessibilidade e adequação para pacientes em cadeira de rodas, em clínicas particulares de fisioterapia na cidade de Goiânia. Em seu estudo, observaram que todas as clínicas avaliadas não obedeceram integralmente às normas da ABNT, sendo que a maioria são adequações de construções previamente existentes. Nesse sentido, as barreiras arquitetônicas poderiam ser evitadas com um planejamento adequado para atender às diferentes necessidades das pessoas portadoras de deficiência e facilitar a vida de todos (COHEN, 1998). A acessibilidade prevista nas etapas iniciais do projeto representa acréscimo de apenas $1 \%$ no valor da obra. Porém, para realizar adaptações depois de construído, o custo pode alcançar $25 \%$. Portanto, é mais viável financeiramente planejar do que adaptar (OLIVEIRA et al., 2005).

Segundo Muniz (2005), engenheira civil e coordenadora técnica do programa Acessibilidade: direito de todos de Brasília, esse investimento é fundamental para garantir o direito de ir e vir com autonomia, independência e segurança e a oportunidade de participação social. É necessária a conscientização e a mobilização da sociedade em 
busca de ações que promovam a acessibilidade e a inclusão social das pessoas portadoras de deficiência ou com mobilidade reduzida.

Santos e Carvalho (2003) realizaram um estudo comparativo sobre as condições de acessibilidade em três clínicas de fisioterapia (pública, privada e filantrópica) em Goiânia e concluíram que o estabelecimento privado é o mais inadequado comparado ao público e ao filantrópico. Mesmo apresentando melhores condições de acesso, os últimos possuem barreiras que podem ser removidas para facilitar o acesso.

A falta de acessibilidade em clínicas particulares de fisioterapia também é observada no presente estudo. As condições de circulação no Plano Piloto, uma localidade com população de bom poder aquisitivo, não são as ideais, visto que não proporciona aos portadores de deficiência o direito à cidadania. Essas pessoas são privadas do acesso aos serviços de saúde e aos estabelecimentos de fisioterapia, fundamentais para a reabilitação, o bem-estar e a melhoria da qualidade de vida.

\section{Conclusão}

Os resultados mostraram que as condições de acesso nas clínicas particulares de Fisioterapia do Plano Piloto de Brasília, em sua maioria, não estão adequadas, de acordo com a NBR 9050:2004, para receber cadeirantes. Mesmo com a existência da legislação e das normas em vigor, há inúmeras barreiras arquitetônicas que impedem os portadores de deficiência física de exercer a plena cidadania.

Geralmente, são realizadas adaptações improvisadas que não resolvem totalmente o problema. Muitos portadores de deficiência evitam freqüentar locais públicos em decorrência das barreiras arquitetônicas existentes. Por essa razão, a sociedade tem a falsa impressão de que há poucas pessoas com necessidades especiais, não sendo necessária remoção dos obstáculos e o gasto com adaptações.

Questiona-se que a maioria dos portadores de deficiência não tenha conhecimento de seus direitos estabelecidos por lei, por isso não luta por mudanças e conforma-se com adaptações precárias. É necessária maior conscientização da sociedade e fiscalização efetiva para garantir a inclusão social dessa parcela significativa da população. 
Esse trabalho mostra a realidade de uma região geograficamente importante, onde se encontra o centro do poder e as leis são aprovadas. Além disso, poderá ser usado como referência para posteriores trabalhos relacionados à acessibilidade, já que existe escassez de estudos na área de Fisioterapia. Porém, os resultados não podem ser extrapolados, pois a amostra é restrita ao Plano Piloto de Brasília. Novos estudos, abrangendo outras regiões, são necessários para descrever a situação do Distrito Federal.

\section{Referências}

ASSOCIAÇÃO OEIRA DE NORMAS TÉCNICAS (ABNT). NBR 9050: 2004.

Acessibilidade de Pessoas Portadoras de Deficiências a Edificações, Espaço, Mobiliário e Equipamento Urbano. Rio de Janeiro, 2004.

BITTENCOUT, L. S. et al. Acessibilidade e Cidadania: Barreiras Arquitetônicas e Exclusão Social dos Portadores de Deficiências Físicas. In: CONGRESSO BRASILEIRO DE EXTENSÃO UNIVERSITÁRIA, 2004, Belo Horizonte. Anais... Disponível em: <www.ufmg.br/congrext/Direitos/Direitos10.pdf>. Acesso em: 14 mai. 2006.

BRASIL. Lei n. 7.853, de 24 de outubro de 1989. Dispõe sobre o apoio às pessoas portadoras de deficiência, sua integração social, sobre a Coordenadoria Nacional para Integração da Pessoa Portadora de Deficiência - Corde, institui a tutela jurisdicional de interesses coletivos ou difusos dessas pessoas, disciplina a atuação do Ministério Público, define crimes, e dá outras providências. Disponível em: $<$ http://www.mj.gov.br/sedh/ct/corde/dpdh/corde/lei7853.asp>. Acesso em: 14 mai. 2006.

Decreto n. 3.298, de 20 de dezembro de 1999. Regulamenta a Lei no 7.853 , de 24 de outubro de 1989, dispõe sobre a Política Nacional para a Integração da Pessoa Portadora de Deficiência, consolida as normas de proteção e dá outras providências. Disponível em: <https://www.planalto.gov.br/ccivil_03/decreto/D3298.htm>. Acesso em: 14 mai. 2006.

Lei n. 10.048, de 8 de novembro de 2000a. Dá prioridade de atendimento às pessoas que especifica, e dá outras providências. Disponível em: <http://www.mj.gov.br/sedh/ct/corde/dpdh/legis1/doc_legis2.asp?id=197>. Acesso em: 14 mai. 2006.

Lei n. 10.098, de 19 de dezembro de 2000b. Estabelece normas gerais e critérios básicos para a promoção da acessibilidade das pessoas portadoras de deficiência ou com mobilidade reduzida, e dá outras providências. Disponível em: 
<http://www.mj.gov.br/sedh/ct/corde/dpdh/legis1/doc_legis2.asp?id=198>. Acesso em: 14 mai. 2006.

COFFITO. Resolução n. 37, de 23 de abril de 1984. Baixa o novo texto do Regulamento para registro de empresas nos Conselhos Regionais de Fisioterapia e Terapia Ocupacional. Disponível em: <www.crefito3.com.br>. Acesso em: 04 set. 2006.

COHEN, R. Estratégias para a Promoção dos Direitos das Pessoas Portadoras de Deficiência. 1998. Disponível em: <www.dhnet.org.br/direitos/sos/def/artigo37.htm>. Acesso em: 14 ago. 2006.

DISTRITO FEDERAL. Lei n. 2.105, de 08 de outubro de 1998. Dispõe sobre o Código de Edificações do Distrito Federal. Disponível em: <http://www.mpdft.gov.br/sicorde/Leg_DF2105-1998.htm>. Acesso em: 14 mai. 2006.

IBGE. Censo Demográfico 2000. Disponível em: <www.ibge.gov.br>. Acesso em: 14 ago. 2006.

GUIMARÃES, M. P. A eliminação de barreiras possibilita aos portadores de deficiência agirem na sociedade. 2002. Disponível em: <www.ceset.unicamp.br/ joaquiml/ST\%20019/Acessibilidade.doc $>$. Acesso em: 14 ago. 2006.

LASCIO, G. R. M. et al. Projeto barreiras arquitetônicas: a arquitetura voltada para os deficientes. 2000. Disponível em: <http://snbu.bvs.br/snbu2000/docs/pt/doc/poster006.doc>. Acesso em: 14 ago. 2006.

LOPES FILHO, J. A. O direito de ir e vir com independência. 2006. Disponível em: $<$ http://www.entreamigos.com.br/textos/acessibi/dirirvir.htm>. Acesso em: 11 jul. 2006.

MAUCH, C. A inclusão das crianças com deficiência na educação infantil, 2004. Disponível em: <www.tvebrasil.com.br/salto/boletins2004/ei/tetxt2.htm>. Acesso em: 14 ago. 2006.

MUNIZ, M. M. B. R. Acessibilidade: questão de cidadania. Revista Reviva. Brasília, ano 2, p. 53-54, 2005.

NICHOLL, A. R. J.; BOUERI FILHO, J.J. O ambiente que promove a inclusão: conceito de acessibilidade e usabilidade. 2001. Disponível em: <www.unimar.br/publicacoes/publicacoes.html>. Acesso em: 14 ago. 2006.

OLIVEIRA, E. T. G. Acessibilidade na Universidade Estadual de Londrina: o ponto de vista do estudante com deficiência. 2003. 197 f. Dissertação (Mestrado) Faculdade de Filosofia e Ciências, Universidade Estadual Paulista. Marília, 2003. Disponível em: <www.biblioteca.unesp.br/bibliotecadigital/document/?did=3447>. Acesso em: 14 ago. 2006. 
OLIVEIRA, R. F. U.; SILVA, R. N.; MACHADO JUNIOR, N. Condições de acessibilidade e adequação, para pacientes em cadeira de rodas, em clínicas de fisioterapia na cidade de goiânia. Goiânia, 2005. Disponível em: $<w w w . w g a t e . c o m . b r / c o n t e u d o / m e d i c i n a e s a u d e / f i s i o t e r a p i a / v a r i e d a d e s . a s p>$. Publicado em 23 abr. 2006.

PEZENTE, J. H. Certidão do Habite-se. 2006. Disponível em: <www.escolher-econstruir.eng.br/Dicas/DicasI/Habite/pag1.htm>. Acesso em: 04 set. 2006.

SANTOS, C. K.; CARVALHO, H. A. Análise das condições de acesso para deficientes físicos em estabelecimentos de fisioterapia. 2003. $94 \mathrm{f}$. Trabalho de Conclusão de Curso (Graduação) - Universidade Católica do Goiás, Goiânia, 2003. Disponível em: <www.ucg.br/fisio/monografia/33.pdf>. Acesso em: 14 ago. 2006. 